\title{
Youth Sports Club Management Mechanism and Operation Mode Devel- opment
}

\author{
Lin Yan*
}

China Institute of Physical Education, Changchun Normal University, Changchun 130032, Jilin, China

\begin{abstract}
Youth sports clubs are popular among youth because it is the main place for the contemporary youth to take sports fitness exercises and complete sports activities, and are convenient to exchange sports experiences,. Therefore, further developed and perfect youth sports club has become one of the important tasks of the current stage youth physical education. The paper starts from introducing youth clubs' personnel structure and its appropriation expenditure situation, and on this basis, respectively establishes youth sports club management mechanism, and operational and optimal solution mode, as well as maximum models of youth sports club organization events. Research on youth sports club development further puts forward that at present youth club faculty level is general, professional athletes are relatively fewer, and sports equipment purchase is the main appropriation expenditure. Results show that holding training classes, taking basketball, football, badminton, swimming and martial arts sports events as the main training contents, building innovation management mechanism into directory system management, can attract more youth to participate in fitness sports clubs, and propel the youth sports club development.
\end{abstract}

Keywords: Management mechanism, Operation mode, Physical health, Sports club.

\section{INTRODUCTION}

As one of the main places for the youth sports activity, youth sports clubs have increasingly introduced reforms for youth sports development. From management system, operation way, to professional staff cultivation, talents selection, sports club's development always has an impact on youth sports development [1].

In the article "Integration of 'Family, school, society' drives sunshine sports long-term mechanism research", Li Chen-Li went deeper into the analysis of important impacts of sunshine sports on the youth's growth with respect to three pillars of family, school and society [2]. The thesis thus investigates sunshine sports application from three aspects based on family, school, and society, collected data from these three groups physical exercises situation, and analyzed sunshine sports running modes [3]. Sunshine sports is a kind of public sports that is made suitable for different age groups and different ethnic groups of people, it not only could enhance physical quality, but also could foster sports consciousness, stimulate sports enthusiasm, and then drive national people to take physical exercises [4].

In the article "Jiangxi province youth sports club development status analysis and countermeasures research", Liu Xiang-Dong took Jiangxi province as an example and specifically conducted research on the province youth sports clubs' development situation.

This study carried out data analysis through statistics of Jiangxi province's all sized youth sports clubs, found

*Address correspondence to this author at the Institute of Physical Education, Changchun Normal University, Changchun 130032, Jilin, China; Tel: +86-13596403977; E-mail: 13596403977@sina.com problems and put forward corresponding solutions [4]. Also, the study pointed out that Jiangxi province youth sports clubs' management and operation have not yet been so perfected, and the government support was not enough. Therefore, in order to promote its further development, government support should be increased, and positive reforms and a perfect management system should be introduced [5].

In the article "Chinese youth sports club operation mode research", Lu Zuo-Sheng carried out research on youth club operational modes as entry point to carry on a deeper analysis [6]. The thesis combined research on Chinese youth sports clubs development history with founding problems emerging from Chinese national conditions. The thesis pointed out that being a country of large population, in the operation and development of youth sports club, China should fully consider the youth, parents and society satisfaction, improve government support, strengthen management, and implement youth sports club operation mode that fits Chinese national conditions [7].

The paper starts from youth sports club management mechanism and operation mode, analyzes their developmental situation, including institution's personnel composition, institution's operation way, management mechanism and so on, and then on the basis of the maximum degree of reduction of appropriation expenditure, to find out the most suitable Chinese youth sports clubs development management mechanism and operation, improving youth sports club's situation and promoting its further development.

\section{YOUTH SPORTS CLUB BASIC INFORMATION}

In youth spare time dominates and sports activity occupies a very large proportion. China provides many 


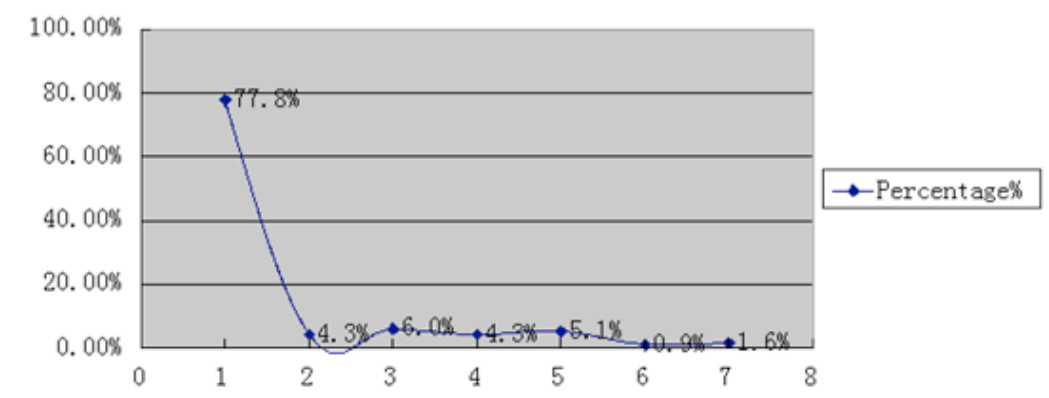

Fig. (1). Youth participation in sports activities.

Table 1. Youth sports activity participation way.

\begin{tabular}{|c|c|c|c|}
\hline & Percentage\% & Rank & No. \\
\hline \hline School sports club & $77.8 \%$ & 1 & 1 \\
\hline Community fitness spot & $4.3 \%$ & 4 & 3 \\
\hline Park & $6.0 \%$ & 2 & 4 \\
\hline Public stadium & $4.3 \%$ & 4 & 5 \\
\hline Operational fitness site & $5.1 \%$ & 3 & 6 \\
\hline Residence & $0.9 \%$ & 6 & 5 \\
\hline Surrounding residence & $1.6 \%$ & 5 & 7 \\
\hline
\end{tabular}

Table 2. Youth sports club faculty situation.

\begin{tabular}{|c|c|c|c|c|}
\hline & $\begin{array}{c}\text { Physical Education } \\
\text { Teacher }\end{array}$ & $\begin{array}{c}\text { Sports Social Instructors } \\
\text { Over Three Grade }\end{array}$ & Coach & Professional Athletes \\
\hline \hline Percentage $\%$ & $42.1 \%$ & $26.5 \%$ & $21.3 \%$ & $10.1 \%$ \\
\hline Rank & 1 & 2 & 3 & 4 \\
\hline
\end{tabular}

places for the youth so as to encourage them to take physical exercises. Table 1 and Fig. (1) offer an analysis of the place selection by the Chinese youth for their sports activity in spare time.

The above analysis shows that $77.8 \%$ youth selected to proceed with sports activities in the school sports club, whereas the rest selected community sports fitness spot and public stadium. The results indicate that the sports club is the most concentration place of youth sports enthusiasts. Therefore, it is advisable for the Chinese government to vigorously manage and operate sports clubs.

\subsection{Youth Sports Club Faculty Team}

In a youth sports club, the faculty strength is not only the main factor that affects the club's standard, but also the key to the youth's satisfaction and stimulant to their sports enthusiasm. Table 2 and Fig. (2) provide analysis of the data on Chinese youth sports club faculty team situation.

The above analysis shows that Chinese youth sports club faculty team's standard is relatively low, among them only $10.1 \%$ are professional athletes, whereas others are physical education teachers, sports social instructors over three grades and coaches. Thus, the personnel composition has not yet been perfected.

\subsection{Youth Sports Club Appropriation Expenditure}

In order to strengthen Chinese youth sports club management, besides its management mechanism and operational way, its appropriation expenditure has also been analyzed, in order to further analyze youth sports club development mode. Table 3 provide analysis of the data on youth sports club main appropriation expenditure situation.

Fig. (3) statistically indicates that most of allocated youth sports club appropriation expenditure, is used to purchase sports equipment, part of it is used to participate in race, besides the rest that is used to manage staff service fee, the coach service fee, publicity expenses and so on. Therefore, purchasing sports equipment is important for a youth sports club.

\section{OPTIMAL SOLUTION MODEL-BASED YOUTH SPORTS CLUB MANAGEMENT SYSTEM RE- SEARCH}

Youth sports club is one of the main places where the youth can undertake sports activities, so its management 


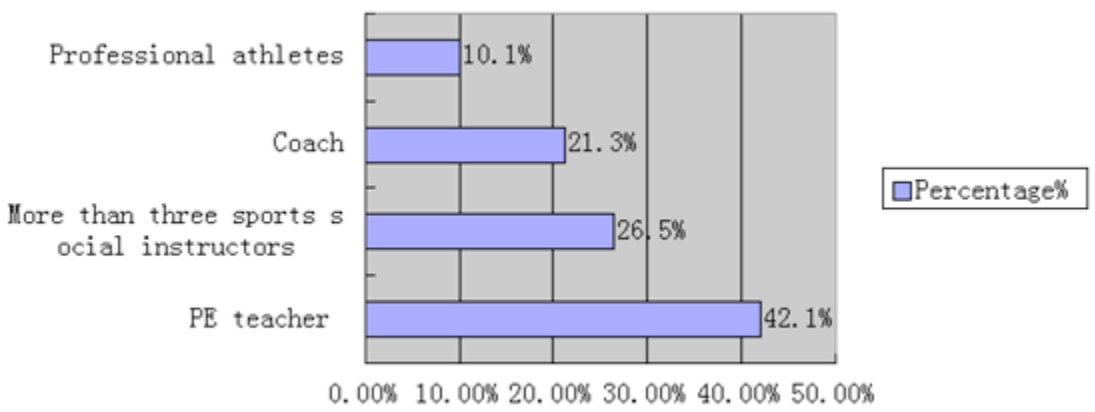

Fig. (2). Youth sports club teaching situation.

Table 3. Youth sports club main appropriation expenditure.

\begin{tabular}{|c|c|c|c|c|c|c|}
\hline & $\begin{array}{c}\text { Cost of Equip- } \\
\text { ment Purchasing }\end{array}$ & $\begin{array}{c}\text { Management } \\
\text { Staff Service Fee }\end{array}$ & $\begin{array}{c}\text { Publicity } \\
\text { Expenses }\end{array}$ & Race Fee & $\begin{array}{c}\text { The Coach } \\
\text { Services Fee }\end{array}$ & Other Expenses \\
\hline \hline Percentage $\%$ & $32.4 \%$ & $6.2 \%$ & $9.5 \%$ & $28.4 \%$ & $10.6 \%$ & $12.9 \%$ \\
\hline
\end{tabular}

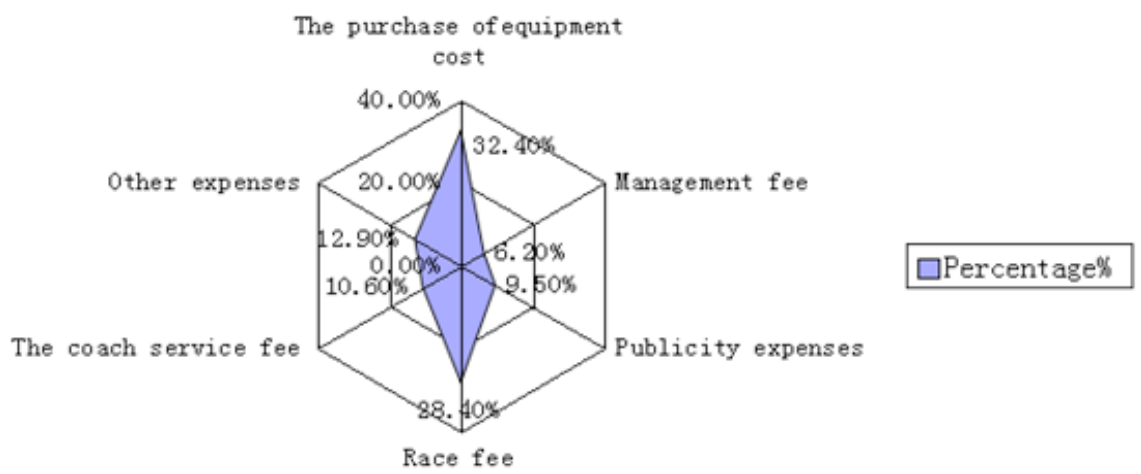

Fig. (3). Major spending of youth sports club.

Table 4. Youth sports club management mechanism.

\begin{tabular}{|c|c|c|c|}
\hline & Director Responsibility System & Board Responsibility System & General Manager Responsibility System \\
\hline \hline Percentage $\%$ & $83.1 \%$ & $13.8 \%$ & $3.1 \%$ \\
\hline Rank & 1 & 2 & 3 \\
\hline
\end{tabular}

mechanism may also restrict its development to a certain degree. So far, sports club mainly has either of the three kinds of management mechanisms: director responsibility system, board responsibility system or general manager responsibility system. Table $\mathbf{4}$ provides Chinese youth sports club management system statistical data.

On the premise that a suitable youth sports club operation optimal management mechanism has the least expenses, it now utilizes goal programming method to solve optimal solution.

\subsection{Goal Programming Guiding Thought}

Goal programming objective function is composed of defined corresponding priority factors according to various objective constraints' positive and negative deviation values. Its common basic form is:
(1) Try to make positive and negative deviation small, and then further just arrive at goal value:

$$
\min z=f\left(d^{+}+d^{-}\right)
$$

Try to make positive deviation small, no need to arrive at goal value:

$$
\min z=f\left(d^{+}\right)
$$

Try to make negative deviation small, surpass goal value and surpass quantity is not limited;

$$
\min z=f\left(d^{-}\right)
$$

Priority factor: $P_{1}, P_{2}, \cdots$, and it has $P_{k} \gg P_{k+1}, k=1,1, \cdots, q$, which represents $P_{k}$ has a higher priority than $P_{k+1}$. 
Table 5. Youth sports club operation mode.

\begin{tabular}{|c|c|c|}
\hline & Percentage $\%$ & Rank \\
\hline \hline Training class & $29.1 \%$ & 1 \\
\hline Winter, summer camp & $19.2 \%$ & 3 \\
\hline Membership system & $18.6 \%$ & 4 \\
\hline Two-day weekends operation & $16.3 \%$ & 5 \\
\hline Night operation & $7.0 \%$ & 6 \\
\hline Temporary random system & $5.2 \%$ & 7 \\
\hline contracted to others to operate & $4.7 \%$ & \\
\hline
\end{tabular}

Goal programming normal mathematical model is :

$$
\begin{aligned}
& \min z=\sum_{k=1}^{q} P_{k}\left(\sum_{j=1}^{l} \omega_{k j}^{-} d_{j}^{-}+\omega_{k j}^{+} d_{j}^{+}\right) \\
& \left\{\begin{array}{l}
\sum_{j=1}^{n} a_{i j} x_{j} \leq(=, \geq) b_{i}, i=1, \cdots, m \\
\sum_{j=1}^{n} c_{i j} x_{j}+d_{i}^{-}-d_{i}^{+}=g_{i}, i=1, \cdots, l \\
x_{j} \geq 0, j=1,2, \cdots, n \\
d_{i}^{-}, d_{i}^{+} \geq 0, i=1,2, \cdots, l
\end{array}\right.
\end{aligned}
$$

\subsection{Goal Programming Data Processing}

According to the above goal programming guiding thought, data processing using data given in Table $\mathbf{4}$ is carried out using a sequential algorithm. Its main process is as follows:

For $k=1,2 \cdots, q$, it solves

$$
\begin{aligned}
& \min z=\sum_{j=1}^{l} P_{k}\left(\sum_{j=1}^{l} \omega_{k j}^{-} d_{j}^{-}+\omega^{+}{ }_{k j} d_{j}^{+}\right) \\
& \sum_{j=1}^{n} a_{i j} x_{j} \leq(=, \geq) b_{i}, i=1, \cdots, m
\end{aligned}
$$

$\sum_{j=1}^{n} c_{i j} x_{j}+d_{i}^{-}-d_{i}^{+}=g_{i}, i=1, \cdots, l$

$\sum_{j=1}^{l}\left(\omega_{s j}^{-} d_{j}^{-}+\omega_{s j}^{+} d_{j}^{+}\right) \leq z_{s}^{*}, s=1,2, \cdots, k-1$

$x_{j} \geq 0, j=1,2, \cdots, n$

$d_{i}^{-}, d_{i}^{+} \geq 0, i=1,2, \cdots, l$

Among them, optimal value is $z_{k}^{*}$
At first, the most important in the priority list is appropriation expenditure, therefore it is the first grade $P_{1}$; secondly, number of youth participants is the second grade $P_{2}$; finally, youth satisfaction is the third grade $P_{3}$. It is required for the appropriation expenditure to be less than $30 \%$. Therefore, a corresponding goal programming model is established as follows:

$$
\begin{aligned}
& \min z=P_{1} d_{1}^{-}+P_{2}\left(d_{2}^{+}+d_{2}^{-}\right)+P_{3}\left(3 d_{3}^{+}+3 d_{3}^{-}+d_{4}^{+}\right) \\
& 0.831 x_{1}+0.138 x_{2}+0.031 x_{3}<0.3 \\
& x_{1}, x_{2}, \cdots, x_{i}, d_{i}^{+}, d_{i}^{-} \geq 0, i=1,2,3
\end{aligned}
$$

Calculate the above objective function by MATLAB software, to further get goal programming optimal solution as follows: $z^{*}=(1)$, that is director management system, and the appropriation expenditure is $21.2 \%$.

\subsection{Optimal Operation Mode Research}

The above analysis shows that on the condition of least youth sports club appropriation expenditure, the most suitable development management mechanism is director management system. Therefore, how to reduce its expenses, is the focus for further study analyzing this operational mode, to get optimal mode of youth sports club operation, see Table 5 for the data and result.

At first, the most important in the priority list is appropriation expenditure, therefore it is the first grade $P_{1}$; secondly, number of youth participants is the second grade $P_{2}$; finally, youth satisfaction is the third grade $P_{3}$. It is required for the appropriation expenditure to be less than $30 \%$. Therefore, a corresponding goal programming model is established as follows:

$$
\begin{aligned}
& \min z=P_{1} d_{1}^{-}+P_{2}\left(d_{2}^{+}+d_{2}^{-}\right)+P_{3}\left(3 d_{3}^{+}+3 d_{3}^{-}+d_{4}^{+}\right) \\
& x_{1}, x_{2}, \cdots, x_{i}, d_{i}^{+}, d_{i}^{-} \geq 0, i=1,2, \cdots, 7
\end{aligned}
$$

Calculate the above objective function by MATLAB software, to further get goal programming optimal solution 
Table 6. Youth sports club organized events.

\begin{tabular}{|c|c|c|c|c|c|}
\hline & Percentage $\%$ & Rank & Percentage\% & Rank \\
\hline \hline Basketball & $21.5 \%$ & 1 & Chess & $2.5 \%$ & $2.5 \%$ \\
\hline Football & $21.5 \%$ & 1 & Tennis & $1.9 \%$ & 7 \\
\hline Badminton & $13.9 \%$ & 2 & Aerobics & $1.3 \%$ & 8 \\
\hline Swimming & $11.4 \%$ & 3 & Parachute from an aircraft & $0.6 \%$ & 9 \\
\hline Martial arts & $11.4 \%$ & Rock climbing & $0.6 \%$ & 9 \\
\hline Volleyball & $6.3 \%$ & 4 & Others & $0.6 \%$ & 9 \\
\hline Go & $3.8 \%$ & 5 & & \\
\hline
\end{tabular}

as follows: $z^{*}=(1)$, that is the form of training class, and the appropriation expenditure is $19.25 \%$.

The above goal programming analysis shows that on the condition that youth sports club expenses are the lowest, the management mechanism and operation mode is the director management system that operates in the form of training class.

\section{MAXIMAL PRINCIPLE-BASED YOUTH SPORTS CLUB ORGANIZED EVENTS RESEARCH}

To propel the development of youth sports club, implementing only reform management mechanism and operation mode is not far enough, it should be commenced from the scratch from analyzing youth demands to organizing their favorite events leading to an all-round development as shown in Table 6.

\subsection{Model Construction and Solution}

According to the above question assumptions, a state equation of youth sports club organized events is obtained when its appropriation expenditures are permitted:

$$
\left\{\begin{array}{l}
\frac{d x\left(t_{1}\right)}{d t_{1}}=-m(t)+g(t) u(t) \\
x(0)=x_{0}
\end{array}\right.
$$

Under the above state equation, an optimal control strategy $u^{*}(t)$ is sought from function set $W$ that meets $0 \leq u(t) \leq U$.

At first, write down question's Hamiltonian function:

$$
H[p x(t)-u(t)] e^{-\delta t}+\lambda[-m(t)+g(t) m(t)]
$$

Then, through costate equation and boundary condition, it solves $\lambda(t)$, that is by

$$
\left\{\begin{array}{l}
\frac{d \lambda(t)}{d t}=-H_{x}=-p e^{-\delta t} \\
\lambda\left(t_{f}\right)=\varphi_{x\left(t_{f}\right)}=e^{-\delta t_{f}}
\end{array}\right.
$$

It solves: $\lambda(t)=\left(1-\frac{p}{\delta}\right) e^{-\delta t_{f}}+\frac{p}{\delta} e^{-\delta t}$

In the following, utilize maximal principal to solve $u^{*}(t)$

For:

$$
H=p x(t) e^{-\delta t}-\lambda m(t)+\left[\lambda g(t)-e^{-\delta t}\right] u(t)
$$

Obviously, $H$ is a linear function of $u$, therefore it can get:

$$
u^{*}(t)= \begin{cases}U, & \lambda g(t)-e^{-\delta t}>0 \\ 0, & \lambda g(t)-e^{-\delta t}<0\end{cases}
$$

Or

$$
u^{*}(t)=\left\{\begin{array}{lc}
U, & {\left[\left(1-\frac{p}{\delta}\right) e^{-\delta t_{f}}+\frac{p}{\delta} e^{-\delta t}\right] g(t)-e^{-\delta t}>0} \\
0, & {\left[\left(1-\frac{p}{\delta}\right) e^{-\delta t_{f}}+\frac{p}{\delta} e^{-\delta t}\right] g(t)-e^{-\delta t}<0}
\end{array}\right.
$$

For breaking point $t_{s}$, it should meet:

$$
\left[\left(1-\frac{p}{\delta}\right) e^{-\delta t_{f}}+\frac{p}{\delta} e^{-\delta t}\right] g(t)-e^{-\delta t}=0
$$

That

$$
\left[\frac{p}{\delta}-\left(\frac{p}{\delta}-1\right) e^{-\delta t_{f}}\right] g(t)-1=0
$$

And then it can solve $t_{s}$.

In the subject, set

$$
x(0)=0.48, U=1, m(t)=2, p=0.1, \delta=0.05, g(t)=\frac{2}{(1+t)^{\frac{1}{2}}}
$$

Therefore, it can get the formula of $t_{s}$ as follows: $\left(1+t_{s}\right)^{\frac{1}{2}}=4-2 e^{0.05\left(t_{s}-t_{f}\right)}$. 
When $t<t_{s}, u^{*}(t)=U=1$, the state equation is:

$$
\frac{d x}{d t}=-2+\frac{2}{(1+t)^{\frac{1}{2}}}
$$

When $t<t_{s}, u^{*}(t)=0$, the state equation is:

$$
\frac{d x}{d t}=-2
$$

So when $t>t_{s}$, it has

$$
\int_{0}^{t} \frac{d x}{d t}=\int_{0}^{t_{s}}\left[-2+\frac{2}{(1+t)^{\frac{1}{2}}}\right] d t+\int_{t_{s}}^{t}(-2) d t
$$

It solves:

$$
\begin{aligned}
& x(t)=4\left(1+t_{s}\right)^{\frac{1}{2}}+96-2 t \\
& t_{f}=2\left(1+t_{s}\right)^{\frac{1}{2}}+28
\end{aligned}
$$

It gets: $t_{s}=10.2, t_{f}=23.8$

Therefore, it gets optimal control strategy that is:

$$
u^{*}(t)= \begin{cases}1, & 10.2 \leq t \leq 23.8 \\ 0, & 0 \leq t \leq 10.2\end{cases}
$$

The above analysis shows that on the condition that youth sports club appropriation expenditure allows, its most suitable events are basketball, football, badminton, swimming and martial arts. Only holding the youth's most favorite events can attract more youth to participate in the club sports activities, leading to youth sports club's development and youth personal physical quality improvement.

\section{CONCLUSION}

Firstly, the paper starts from analyzing youth sports club's basic information, researches on youth amateur sports activity mode, place selection, youth sports club personnel structure and its appropriation expenditure situation. Then, the study moves on with that the youth sports club is the main optional exercise place where Chinese youth takes fit- ness sports exercises, its faculty level is general, professional athletes are relatively few, and most of available appropriation expenditures are used to purchase sports equipment. Secondly, the paper respectively establishes youth sports club management mechanism and operation mode for optimal solution, as well as youth sports club organization events maximum model, and performs a deeper analysis of the management system to find an operation mode that is most suitable for Chinese youth sports club development on the condition of least appropriation expenditure. The paper also puts forward which events are the youth's favorite sports. In conclusion the director management system is the most suitable management mechanism for youth sports club, and operation mode should be based on training classes. Finally, a club should focus on holding sports events such as basketball, football, badminton, swimming and martial arts so as to attract more youth to participate in sports club fitness.

\section{CONFLICT OF INTEREST}

The author confirms that this article content has no conflict of interest.

\section{ACKNOWLEDGEMENTS}

Declared none.

\section{REFERENCES}

[1] L. Cai, and J. Jia, "The role of local government in MICE," Journal of Huazhong University of Science and Technology(Social Science Edition), vol. 21, no. 5, pp. 67-70, 2007

[2] J. Dong, "Existing mainly problems, reasons and countermeasures about china host mega sport events," Sports \& Science, vol. 33, no. 3, pp. 42-51, 2012.

[3] L. Huang, and X. Fu, "On the connotation of sports events," Journal of Capital College of Physical Education, vol. 17, no. 6, pp. 12$13,2005$.

[4] H. Huang, L. Zhang, and N. Li, "Study on the role of shanghai government in the operation of major sports competition events," China Sport Science, vol. 27, no. 2, pp. 17-25, 2007.

[5] G. Lu, and X. Liu, "Study on the choice of policy of sports industry development during construction of well - off society in shaanxi province," Journal of Xi'an Institute of Physical Education, vol. 23 no. 5, pp. 44-46, 2006.

[6] C. Ren, and J. Zhang, "The research on macro-environment of china's sports competition exhibition match industry market," Sports \& Science, vol. 25, no. 3, pp. 14-17, 2004.

[7] L. Zhou, X. Chen, and X. Zhou, "Status and role of government in sport event exhibition industry: taking shanghai as an example," Sports Science Research, vol. 28, no. 4, pp. 48-51, 2007. 